\title{
Measuring Railway Efficiencies with Consideration of Input Congestion
}

\author{
Erwin T. J. Lin ${ }^{1}$, Lawrence W. Lan², Jeng-Cheng Chang ${ }^{3}$ \\ ${ }^{1}$ Department of Global Marketing and Logistics, MingDao University, Changhua, Taiwan \\ ${ }^{2}$ Department of Television \& Internet Marketing Management, Ta Hwa Institute of Technology, Taiwan \\ ${ }^{3}$ Department of Business Innovation and Development, MingDao University, Taiwan \\ Email: erwintjlin@mdu.edu.tw
}

Received June 26, 2012; revised July 28, 2012; accepted August 18, 2012

\begin{abstract}
Input congestion very likely existed in rail transport. However, early works measuring the rail transport efficiencies rarely took the input congestion into account; hence, the proposed strategies for enhancing efficiencies can be misleading. This study revisited the rail transport efficiencies with consideration of input congestion. We employed data envelopment analysis extension method to investigate the input congestion for some selected 24 European Union (EU) railways in 2006. The results indicated that there is no strong congestion in these 24 railways. However, 12 railways have been diagnosed with weak congestion in the available capacity of freight transport as well as the number of locomotives, 7 railways in the available capacity of passenger transport, and 4 railways in the number of employees. Based on our findings, the managerial implication is to contract the available capacity of freight transport (tonnages) as the most critical strategy, rather than laying-off the excess number of employees suggested by most previous studies, which did not consider the input congestion effects while measuring the rail transport efficiencies.
\end{abstract}

Keywords: Data Envelopment Analysis; Input Slack; Input Congestion; Rail Transport

\section{Introduction}

Rail transport has long been playing a critical role in developing different countries' economics; however, numerous railways have significantly lost business to other modes, such as highway and air, over the past decades. Some have even been suffering from serious financial deficit. Taking the freight transport as an example, the market share (ton-km) for European Union (EU) railways has declined from $32 \%$ in 1970 to $12 \%$ in 1999 [1]. The decline of railway market could be attributed to relatively higher level-of-service of other modes; e.g., truckers can deliver furniture from Lyon, France to Milan, Italy in eight hours, while railways need forty-eight hours [2]. It could also be attributed to rail's poor performance in productive efficiency [3]. To be more competitive for the rail transport, enhancing the productive efficiency should be viewed as an important strategy. Rail transport is in effect a labor- and capital-intensive industry. On one hand, the operation of railways inevitably encounters the constraints of labor law. On the other hand, railways are usually subject to limitations of system capacity in yards, lines, and/or stations, which may result in input congestion phenomena.

Due mainly to public-owned, most railways are lack of autonomy; thus, laying-off the excess labor is normally prohibited either by the labor unions or by the government regulations. Consequently, overstaffing problem oftentimes exhibit in this industry. However, overstaffing is not the only source of input congestion for railways; other factors may also result in congestive effects. For instance, too many cars and/or locomotives allocated in a yard or a depot would certainly hinder the efficiency of trains formation and the overall operation. In the past, a considerable number of works have endeavored to rail transport performance evaluation, but these works did not take input congestion into account. Investigating the relative technical efficiency in rail transport and scrutinizing the possible sources of inefficiency would assist the managers not only to learn from the benchmarked companies but also to propose more decisive strategies to rectify the inefficiency. Based on this, this study aims to measure the efficiency of rail transport with consideration of input congestion.

Based on literature, the input congestion effect can either be expressed in terms of excessive inputs [4-6], or be measured in terms of shortfall in outputs $[7,8]$. In this study we measure the input congestion effect from output point of view; namely, we regard "input congestion" as whenever increasing one or more inputs will decrease some outputs without improving other inputs or outputs. 
The input congestion can further be divided into two kinds: strong and weak, according to [8]. Strong congestion is regarded as an activity that a proportionate reduction in all inputs will warrant an increase in all outputs; while weak congestion is regarded as an activity such that uses less resources in one or more inputs for making more products in one or more outputs. We believe that rail transport is very likely existent with input congestion, either strong or weak. This study will conduct an empirical test on the efficiency and input congestion for some selected EU railways. Using the Data Envelopment Analysis (DEA) extension method, proposed by [8], we first evaluate the technical efficiency and then detect if strong or weak congestion exhibit for the samples. For those railways detected with input congestion, we further identify the sources and amounts of congestion, and then propose more decisive strategies to correct the poor efficiency.

The remaining parts of this paper are arranged as follows. Section 2 reviews some relevant studies. Section 3 describes the methodology. Section 4 presents the empirical results. Some discussions and concluding remarks are addressed in the last section.

\section{Literature Review}

The Data Envelopment Analysis (DEA) method, first developed by Charnes et al. [9], has been widely used in performance evaluation. Many studies, including theoretical developments and practical applications, have been published in literature in the past three decades. Since the DEA method has some advantages (e.g., one can handle multi-output multi-input production technologies without the need of specifying the functional form in prior), many researchers measure the technical efficiency for railways by different DEA approaches. For example, Oum and $\mathrm{Yu}[10]$ applied DEA to evaluate the efficiency of 19 OECD countries' rail companies over the period of 1978 to 1989. Chapin and Schmidt [11] used the DEA to measure the efficiency of US Class I railroad companies since deregulation. Cowie [12] also applied the DEA to compare the efficiency of Swiss public and private railways by constructing technical and managerial efficiency frontiers and then measured both efficiencies. Lan and Lin [13] further proposed a fourstage DEA model to evaluate rail transport efficiency, effectiveness, productivity, and marketing capability. The aforementioned works have endeavored to measure the performance of rail transport in the past; however, none have taken input congestion effect into account.

Conventional DEA models implicitly assume that each firm can always freely dispose overused input factors. The treatment of congestion of input factors in the technical efficiency measurement context was probably pioneered by Färe and Svensson [14], who referred to Tur- got's "law of variable proportions" and distinguished three different strengths of congestion of production factors, including output-limitational congested, monotone output-limitational congested, and output-prohibitive congested. Färe et al. [4] subsequently proposed an operational input-oriented weak disposal DEA model for dealing with input congestion measurement. Using a slack-based DEA approach proposed by Cooper et al. [15], Brockett et al. [16] estimated the inefficiency and amounts of input congestion in the Chinese empirical production before and after the 1978 economy reforms. Their results indicated that textiles, chemicals and metallurgy industries all exhibited input slacks due to the huge labor employment problem and all slacks of labor input in each industry were attributed to congestion. Cooper et al. [6] also adopted same approach to identify congestive inputs in Chinese textiles and automobiles industries. The results showed that elimination of managerial inefficiencies could have led to output augmentation without reducing employment, and even in the heavily congested textile industry, these output augmentations could have been accompanied by reductions in the amounts of capital used. Tone and Sahoo [8] developed a new scheme to evaluate scale elasticity in the presence of input congestion and then applied their new method to a data set obtained from the Japan Chain Store Association. The results indicated that the Association had been operating under Decreasing Returns to Scale (DRS) for the last ten years. Their findings are useful for managers to reform their business.

Based on previous literature, we note that at least three methods for measuring the input congestion have been developed: Färe-Grosskopf-Lovell (FGL) method by Färe et al. [4], Cooper-Thompson-Thrall (CTT) method by Cooper et al. [15], and Tone-Sahoo (TS) method by Tone and Sahoo [8]. These three methods differ most fundamentally_FGL method used a radial Farrell [17] measure, while CTT and TS methods used a slack-based measure to identify the input(s) responsible for congestion. The key difference between CTT and TS methods lie in the point of view-CTT method measures congestion in terms of excessive input(s) while TS method in terms of output shortfall. In addition, TS method measures scale elasticity before identifying congestion while CTT method does not. By definition, input congestion occurs whenever increasing one or more inputs will decrease some outputs without improving other inputs or outputs. In other words, it is meaningful and useful to identify presence of input congestion by checking whether its scale elasticity is negative. In this sense, measuring congestion from output point of view and calculating scale elasticity in advance seems more logical. We thus adopt TS method in this study, which will be narrated in detail later. 


\section{Methodology}

\subsection{Measuring Technical Efficiency and Slack}

The production technology can be represented by the production possibility set containing all feasible input and output vectors: $P=\{(x, y) \mid x$ can produce $y\}$. That is, one can define the production possibility set as $P=\{(x, y) \mid x \geqq X \lambda, y \leqq Y \lambda, \lambda \geqq 0) \in T\}$, where $x=\left(x_{1}, x_{2}\right.$, $\left.\cdots, x_{m}\right) \in R_{+}^{k}$, and $y=\left(y_{1}, y_{2}, \cdots, y_{k}\right) \in R_{+}^{k} . P$ is closed, bounded, convex, and satisfies strong disposability. Once the production possibility set is defined, the efficiency can be measured by the distance from the observed data point to the best feasible practice (frontier), which can be solved by the Linear Programming (LP) technique.

Assume that there are $J$ Decision Making Units (DMUs), $J=\{1, \cdots, J\}$, each produces $K$ outputs, $K=\{1$, $\cdots, K\}$, by utilizing $M$ inputs, $M=\{1, \cdots, M\}$. Charnes et al. [9] proposed to measure the technical efficiency for $\mathrm{DMU}_{i}$ which is known as CCR model in an output-oriented form. The CCR model implicitly assumes that all DMUs are operated at its optimal scale, that is, under the assumption of constant returns to scale (CRS). However, it is believed that this may not be the case in practice. To relax this assumption, Banker et al. [18] proposed the following model, which is known as BCC model, to account for variable returns to scale (VRS).

$$
\begin{array}{ll}
\operatorname{Max}_{\phi, \lambda} & \phi_{i} \\
\text { s.t. } & -\phi_{i} \cdot y_{i k}+\sum_{j=1}^{J} \lambda_{j} y_{j k}-s_{k}^{+}=0, \quad k=1, \cdots, K, \\
& x_{i m}-\sum_{j=1}^{J} \lambda_{j} x_{j m}-s_{m}^{-}=0, \quad m=1, \cdots, M, \\
& \sum_{j=1}^{J} \lambda_{j}=1, \lambda \geq 0, j=1, \cdots, J
\end{array}
$$

where $1 / \varphi_{i}$ is the efficiency of $\mathrm{DMU}_{i}$ to be evaluated, $s^{+}$ and $s^{-}$are output and input slacks, respectively. Solving (1) for each of $J$ firms, one obtains the efficiency score for each firm. To measure $s^{+}$and $s^{-}$, Ali and Seiford [19] suggested employing a two-stage method: obtain $\varphi_{i}$ by solving (1) and then solve the following LP, keeping the objective function value at optimal $\varphi_{i}$.

$$
\begin{gathered}
\operatorname{Max}\left(\sum_{k=1}^{K} s_{k}^{+}+\sum_{m=1}^{M} s_{m}^{-}\right) \\
\text {s.t. } \phi_{i} \cdot y_{i k}=\sum_{j=1}^{J} \lambda_{j} y_{j k}-s_{k}^{+}, \quad k=1, \cdots, K, \\
x_{i m}=\sum_{j=1}^{J} \lambda_{j} x_{j m}+s_{m}^{-}, \quad m=1, \cdots, M, \\
\sum_{j=1}^{J} \lambda_{j}=1, \lambda_{j} \geq 0, j=1, \cdots, J
\end{gathered}
$$

Once $\varphi, s^{+}$and $s^{-}$are computed, Tone and Sahoo [8] suggested the following four conditions to identify congestion: 1) if $\phi^{*}=1, s^{-*}=0$ and $s^{+^{*}}=0$, then the DMU is efficient and not congested; 2) if $\phi^{*}=1, s^{-*} \neq 0$ and $s^{+^{*}}=0$, then the DMU is technically inefficient, but not congested because there is no output shortfall; (3) if $\phi^{*}=1$ and $s^{+^{*}} \neq 0$, or (4) if $\phi^{*}>1$, then the DMU exhibits congestion. In this study, we will use these four conditions to identify the existence of input congestion.

\subsection{Measuring Scale Elasticity}

Following Banker et al. [18], the dual form to (1) is expressed as follows:

$$
\begin{array}{ll}
\text { Min } & \sum_{m=1}^{M} v_{m} x_{o m}-\omega_{o} \\
\text { s.t. } & -\sum_{m=1}^{M} v_{m} x_{j m}+\sum_{k=1}^{K} u_{k} y_{j k}+\omega_{j} \leq 0, j=1, \cdots, J, \\
& \sum_{k=1}^{K} u_{k} y_{o k}=1, \\
& v \geq 0, u \geq 0, \omega_{o}: \text { free in sign }
\end{array}
$$

Banker et al. [18] showed that the optimal solution of $\omega_{o}$ can be used to derive the scale economies. In many occasions, however, the optimal $\omega^{*}$ is not uniquely determined; in such case, Tone and Sahoo [8] proposed to find the upper bound $(\bar{\omega})$ and lower bound $(\underline{\omega})$ by solving the following LP.

$$
\begin{array}{ll}
\bar{\omega}(\underline{\omega})=\operatorname{Max}(\operatorname{Min}) \omega_{o} \\
\text { s.t. } & -\sum_{m=1}^{M} v_{m} x_{j m}+\sum_{k=1}^{K} u_{k} y_{j k}+\omega_{j} \leq 0, j=1, \cdots, J, \\
& -\sum_{m=1}^{M} v_{m} x_{o m}+\sum_{k=1}^{K} u_{k} y_{o k}+\omega_{o}=0, \\
& \sum_{k=1}^{K} u_{k} y_{o k}=1, \\
& v \geq 0, u \geq 0, \omega_{o}: \text { free in sign }
\end{array}
$$

Once the upper (lower) bound of $\omega$ is calculated, the upper (lower) scale elasticity in production $\bar{\rho}(\underline{\rho})$ can be determined by

$$
\bar{\rho}=1+\bar{\omega} \text { and } \underline{\rho}=1+\underline{\omega}
$$

\subsection{Measuring Strong Congestion}

If a DMU is identified as congestive, then we may need to further find out the source(s) of congestion. First, we define strong congestion as "an increase (decrease) in all inputs will lead to a decrease (increase) in all outputs," according to Tone and Sahoo [8]. Second, the efficiency under the strong disposability assumption can be measured by the following LP: 


$$
\begin{array}{ll}
\operatorname{Max}_{\vartheta, \lambda} \theta_{i} & \\
\text { s.t. } & -\theta_{i} \cdot y_{i k}+\sum_{j=1}^{J} \lambda_{j} y_{j k}-q_{k}^{+}=0, \quad k=1, \cdots, K, \\
& x_{i m}-\sum_{j=1}^{J} \lambda_{j} x_{j m}=0, \quad m=1, \cdots M, \\
\sum_{j=1}^{J} \lambda_{j}=1, \lambda \geq 0, j=1, . \cdots J
\end{array}
$$

where $q_{k}^{+}$is output shortfall. Note that Equation (6) differs from Equation (1) in the second constraint where inequality is replaced by equality. To find out $q_{k}^{+}$, one has to use a two-stage method in the same manner as in Equation (2). Similar to Banker et al. [18], the dual problem to Equation (6) can be formulated as follows:

$$
\begin{array}{ll}
\text { Min } & \sum_{m=1}^{M} v_{m} x_{o m}-w_{o} \\
\text { s.t. } & -\sum_{m=1}^{M} v_{m} x_{j m}+\sum_{k=1}^{K} u_{k} y_{j k}+w_{j} \leq 0, j=1, \cdots, J, \\
& \sum_{k=1}^{K} u_{k} y_{o k}=1, \\
& u \geq 0, \quad v, \quad w_{o}: \text { free in sign }
\end{array}
$$

Note that in Equation (7) $v$ is free in sign, which allows the frontier to bend downward. In other words, the frontier can have negative slopes. The multiple optima in Equation (7) can also be dealt with by the following:

$$
\begin{gathered}
\bar{w}=\operatorname{Max} w_{o} \\
\text { s.t. } \quad-\sum_{m=1}^{M} v_{m} x_{j m}+\sum_{k=1}^{K} u_{k} y_{j k}+w_{j} \leq 0, j=1, \cdots, J, \\
-\sum_{m=1}^{M} v_{m} x_{o m}+\sum_{k=1}^{K} u_{k} y_{o k}+w_{o}=0, \\
\sum_{k=1}^{K} u_{k} y_{o k}=1, \\
u \geq 0, \quad v, \quad w_{o}: \text { free in sign }
\end{gathered}
$$

The upper bound of scale elasticity can be calculated by $\bar{\rho}=1+\bar{\omega}$. Following Tone and Sahoo [8], in this paper we define strong congestion as "a DMU is identified as strong congestion if and only if its upper bound of scale elasticity is negative."

\subsection{Measuring Weak Congestion}

Since the strong congestion defined in the previous subsection is too restricted, we thus relax the restriction to the weak congestion, which is defined as "weak congestion occurs whenever an increase (decrease) in one or more inputs will lead to a decrease (increase) in one or more outputs." Notice that strong congestion implies weak congestion but not vice versa. To measure weak congestion, we calculate $t_{k}^{+}$and $t_{m}^{-}$by a two-stage me- thod; that is, solve the following Equation (9) and then Equation (10).

$$
\begin{array}{ll}
\operatorname{Max} & \sum_{k=1}^{K} \frac{t_{k}^{+}}{y_{k o}} \\
\text { s.t. } & x_{m o}=\sum_{j=1}^{n} \lambda_{j} x_{i j}+t_{m}^{-}, \quad m=1,2, \cdots, M \\
& y_{k o}=\sum_{j=1}^{n} \lambda_{j} y_{k j}-t_{k}^{+}, \quad k=1,2, \cdots, K \\
& \sum_{j=1}^{n} \lambda_{j}=1, \lambda_{j} \geq 0, t_{m}^{-}, t_{k}^{+} \geq 0 . \\
\text { Max } \quad \sum_{m=1}^{M} \frac{t_{m}^{-}}{x_{m o}} & x_{m o}=\sum_{j=1}^{n} \lambda_{j} x_{m j}+t_{m}^{-}, \quad m=1,2, \cdots, M \\
\text { s.t. } & y_{k o}=\sum_{j=1}^{n} \lambda_{j} y_{k j}-t_{k}^{+}, \quad k=1,2, \cdots, K \\
& \sum_{j=1}^{n} \lambda_{j}=1, \lambda_{j} \geq 0, t_{m}^{-}, \quad t_{k}^{+} \geq 0 .
\end{array}
$$

In Equation (10), $t_{k}^{+}$is the optimal solution of Equation (9). Once $t_{k}^{+}$and $t_{m}^{-}$are calculated, we have the following two cases. (1) If $t_{k}^{+^{*}}=0$, no weak congestion is detected since a decrease in inputs cannot increase any output. (2) If $t_{k}^{+^{*}} \neq 0$ and $t_{m}^{-*} \neq 0$, then DMU is identified with weak congestion. In this case, Tone and Sahoo [8] further defined an approximation to the marginal production rate (MPR), which can be viewed as a proxy measure of scale elasticity. Tone and Sahoo [8] proposed to calculate the Degree of Scale Economies (DSE) by the follows.

$$
\mathrm{DSE}=\frac{\mathrm{MPR}}{\mathrm{APR}}=-\frac{1}{\bar{K}} \sum_{k=1}^{K} \frac{t_{k}^{+}}{y_{k o}} / \frac{1}{\bar{M}} \sum_{m=1}^{M} \frac{t_{m}^{-}}{x_{m o}}
$$

\section{Empirical Study}

\subsection{The Data}

Our data set is drawn from International Railway Statistics, published by the International Union of Railways [20]. Note that when applying DEA to evaluate the performance, the DMUs under consideration should be homogeneous [21]. In this study we attempt to analyze the efficiency and identify possible source(s) of input congestion of railways, we thus selected 24 railways in the 20 member countries of European Union. All of these railways provide both passenger and freight services. Those railways without complete operation data, such as ATOC (UK), CIE (Ireland), and providing only passenger or freight transport service, such as SJ (Sweden), NS (Netherlands), DSB (Denmark), NIR (UK), and Eurostar 
(UK) are excluded from our data set.

Following Coelli and Perelman [22,23], we choose passenger-kilometer and ton-kilometer as output variables. As for the input variables, some studies selected number of employees, number of cars, and length of lines as inputs. But we do not use length of lines because for rail transport industry, line-related facilities such as tracks, signals, stations and yards can be viewed as sunk cost, which are generally attributed to "fixed" costs. In this paper, we attempt to measure the efficiency of "variable" input factors so as to identify the input congestion. As for the input of rolling stock, because the passenger (freight) service cannot be produced by freight (passenger) cars, therefore, instead of the sum of cars, we select available capacity of passenger transport (in terms of number of seats), available capacity of freight transport (in terms of number of tonnages) as two input factors. In addition, we also choose the number of employees and the number of locomotives as the input variables. Table 1 presents the descriptive statistics for the data, including four inputs and two outputs.

\subsection{The Results}

We estimate efficiency scores, slacks, and identify possible congestion for 24 samples by different DEA models utilizing the software GAMS 2.50 [24]. The detailed analysis results for each DMU are presented in Table 2 through Table 5. Based on the results and extended analysis, some important findings are summarized and discussed as follows.

\subsubsection{Testing Homogeneity}

To test the hypothesis of homogeneity, we classify the samples into two groups: Eastern Europe and Western Europe. Each group has 12 railways and their efficiencies are evaluated by Equation (1) - BCC model; the results are indicated in Table 2. Note that those DMUs evaluated as inefficient can be brought into efficient as defined by $x_{o}^{*} \leftarrow x_{o}-s^{-^{*}}, y_{o}^{*} \leftarrow \varphi \cdot y_{o}+s^{+^{*}}$. After projection, reevaluate the efficiency by pooling all samples together, the efficiency and its ranking are also displayed in Table 2.

Table 1. The descriptive statistics for 24 EU railways.

\begin{tabular}{ccccc}
\hline Variables & Min & Max & Mean & Stdev \\
\hline No. of employees $\left(x_{1}\right)$ & 420 & 157,509 & 25,861 & 37,271 \\
No. of locomotives $\left(x_{2}\right)$ & 4 & 4161 & 1005 & 1363 \\
No. of seats $\left(x_{3}\right)$ & 2355 & $1,362,252$ & 253,703 & 381,243 \\
No. of tonnages $\left(x_{4}\right)$ & 840 & $4,702,000$ & 964,821 & $1,255,395$ \\
Passenger-kilometers $\left(y_{1}\right)$ & 120 & 78,465 & 12,269 & 22,214 \\
Ton-kilometers $\left(y_{2}\right)$ & 12 & 88,407 & 14,214 & 19,456 \\
\hline
\end{tabular}

Table 2. The efficiencies \& rankings for 24 railways.

\begin{tabular}{|c|c|c|c|c|}
\hline Railways & $\varphi_{W E}$ & $\varphi_{E E}$ & $\varphi_{A P}$ & Ranking \\
\hline GKB & 1 & - & 1 & 6.5 \\
\hline ÖBB & 1 & - & 1.104 & 15 \\
\hline SNCB & 1.317 & - & 1.159 & 18 \\
\hline VR & 1 & - & 1.077 & 14 \\
\hline SNCF & 1 & - & 1 & 6.5 \\
\hline DB AG & 1 & - & 1 & 6.5 \\
\hline FS & 1.069 & - & 1 & 6.5 \\
\hline $\mathrm{CFL}$ & 3.716 & - & 1.105 & 16 \\
\hline $\mathrm{CP}$ & 1 & - & 1.117 & 17 \\
\hline Euskotren & 1 & - & 1 & 6.5 \\
\hline FGC & 1 & - & 1 & 6.5 \\
\hline RENFE & 1 & - & 1 & 6.5 \\
\hline $\mathrm{BDZ}$ & - & 1.325 & 1.575 & 22 \\
\hline $\mathrm{CD}$ & - & 1.092 & 1.255 & 19 \\
\hline EVR & - & 1 & 1 & 6.5 \\
\hline OSE & - & 1 & 1.020 & 13 \\
\hline GYSEV & - & 1 & 1 & 6.5 \\
\hline MAV & - & 1 & 1.771 & 23 \\
\hline LDZ & - & 1 & 1 & 6.5 \\
\hline LG & - & 1.069 & 1 & 6.5 \\
\hline PKP & - & 1 & 1 & 6.5 \\
\hline CFR & - & 1 & 2.075 & 24 \\
\hline ZSSK & - & 1 & 1.382 & 21 \\
\hline $\mathrm{SZ}$ & - & 1.337 & 1.274 & 20 \\
\hline Average & 1.259 & 1.069 & 1.163 & \\
\hline
\end{tabular}

Note: $\varphi_{W E}, \varphi_{E B}, \varphi_{A P}$ stand for efficiencies of West Europe, East Europe, and after projection.

To test whether there is significant difference between Eastern and Western Europe, Mann-Whitney U test is adopted. The mean $\left(\mu_{w}\right)$, standard deviation $\left(\sigma_{w}\right)$, and $\mathrm{z}$-value are $150,17.32$, and 1.38 , respectively. Then $\mathrm{p}$-value $=2(0.5-0.4162)=0.1676$, which is greater than 0.05 , suggesting that the null hypothesis of no technological difference between the railways of Eastern and Western Europe groups cannot be rejected at 5\% level of significance.

\subsubsection{Efficiencies, Input and Output Slacks}

After testing homogeneity, we evaluate the efficiency for each of 24 DMUs and calculate input and output slacks; 
the results are indicated in Table 3. As one can see from Table 3, the mean efficiency of 24 railways is 0.739 (1/1.353), suggesting that, on average, railways in the sample should expand their outputs by 35.3 percent, while keeping inputs unchanged. For the input slacks, Table 3 shows that of these 24 DMUs, 13 railways are identified with slacks in number of tonnages (averaged 171 thousand tons) and number of locomotives (averaged 170 locomotives), 7 railways with slack in number of employees (averaged 1623 employees) and 6 railways with slack in number of seats (averaged 11 thousand seats). As for the output slacks, only one railway is identified with slack in passenger transport service (22 million passenger-kilometers) and two railways with slack in freight service (averaged 170 million ton-kilometers).

Table 3. The input and output slacks for 24 railways.

\begin{tabular}{|c|c|c|c|c|c|c|c|}
\hline \multirow{2}{*}{ Railways } & \multirow{2}{*}{$\varphi$} & \multicolumn{4}{|c|}{$s^{-}$} & \multicolumn{2}{|c|}{$s^{+}$} \\
\hline & & $x_{1}$ & $x_{2}$ & $x_{3}$ & $x_{4}$ & $y_{1}$ & $y_{2}$ \\
\hline GKB & 1 & 0 & 0 & 0 & 0 & 0 & 0 \\
\hline ÖBB & 1.104 & 0 & 589 & 28,844 & 0 & 0 & 0 \\
\hline SNCB & 1.526 & 0 & 31 & 46,348 & 23 & 0 & 0 \\
\hline VR & 1.077 & 0 & 294 & 0 & 68,601 & 0 & 0 \\
\hline SNCF & 1 & 0 & 0 & 0 & 0 & 0 & 0 \\
\hline $\mathrm{DB} A G$ & 1 & 0 & 0 & 0 & 0 & 0 & 0 \\
\hline FS & 1.069 & 439 & 928 & 0 & 783,116 & 0 & 3803 \\
\hline CFL & 4.104 & 210 & 36 & 0 & 125,393 & 0 & 0 \\
\hline $\mathrm{CP}$ & 1.117 & 0 & 7 & 18,297 & 66 & 0 & 0 \\
\hline Euskotren & 1 & 0 & 0 & 0 & 0 & 0 & 0 \\
\hline FGC & 1 & 0 & 0 & 0 & 0 & 0 & 0 \\
\hline RENFE & 1 & 0 & 0 & 0 & 0 & 0 & 0 \\
\hline $\mathrm{BDZ}$ & 2.086 & 11,097 & 360 & 0 & 369,090 & 0 & 0 \\
\hline $\mathrm{CD}$ & 1.371 & 0 & 990 & 112,895 & 338,298 & 0 & 0 \\
\hline EVR & 1 & 0 & 0 & 0 & 0 & 0 & 0 \\
\hline OSE & 1.02 & 0 & 111 & 9012 & 39,507 & 0 & 281 \\
\hline GYSEV & 1 & 0 & 0 & 0 & 0 & 0 & 0 \\
\hline MAV & 1.771 & 19,878 & 522 & 0 & 68,159 & 0 & 0 \\
\hline LDZ & 1 & 0 & 0 & 0 & 0 & 0 & 0 \\
\hline LG & 1.069 & 0 & 30 & 0 & 226,609 & 520 & 0 \\
\hline PKP & 1 & 0 & 0 & 0 & 0 & 0 & 0 \\
\hline CFR & 2.075 & 1196 & 111 & 0 & $1,498,749$ & 0 & 0 \\
\hline ZSSK & 1.382 & 4543 & 0 & 63,157 & 545,222 & 0 & 0 \\
\hline $\mathrm{SZ}$ & 1.703 & 1657 & 68 & 0 & 54,155 & 0 & 0 \\
\hline Average & 1.353 & 1626 & 170 & 11,606 & 171,541 & 22 & 170 \\
\hline
\end{tabular}

We also note from Table 3 that 10 railways, such as SNCF (France), DB (Germany), RENFE (Spain), are evaluated as efficient and without slack $\left(\varphi=1, s^{+}, s^{-}=0\right)$. Moreover, 11 railways, such as CFL (Luxembourg), BDZ (Bulgaria), and CFR (Romania) are inefficient but without output slack $\left(\varphi>1, s^{+}=0\right)$. Finally, FS SpA (Italy), OSE (Greece), and LG (Lithuania) are inefficient and with output slack $\left(\varphi>1, s^{+}>0\right)$.

\subsubsection{Strong Congestion and Week Congestion}

To investigate strong congestion, we measure the efficiency and output shortfall under the assumption of strong disposability (Equation (6)). The results, including efficiency $(\theta)$, output shortfall $\left(q^{+}\right)$, and scale elasticity $(\bar{\rho})$ are presented in Table 4. As can be seen from Table 4, all railways are evaluated as weakly efficient (with $\theta$ $=1$, and $q^{+}=0$ ) with exceptions of SNCB (Belgium) and SZ (Slovakia). Furthermore, the upper bounds of scale elasticities are all greater than zero, suggesting that there is no strong congestion in the sample.

Table 4. The results of strong congestion.

\begin{tabular}{|c|c|c|c|c|}
\hline \multirow{2}{*}{ Railways } & \multirow{2}{*}{$\theta$} & \multicolumn{2}{|c|}{$q^{+}$} & \multirow{2}{*}{$\bar{\rho}$} \\
\hline & & Pax-kms & Ton-kms & \\
\hline GKB & 1 & 0 & 0 & 1.347 \\
\hline ÖBB & 1 & 0 & 0 & 0.949 \\
\hline SNCB & 1.340 & 5442 & 0 & 0.970 \\
\hline VR & 1 & 0 & 0 & 1.409 \\
\hline SNCF & 1 & 0 & 0 & 1.002 \\
\hline DB AG & 1 & 0 & 0 & 0.992 \\
\hline FS & 1 & 0 & 0 & 1.000 \\
\hline CFL & 1 & 0 & 0 & 88.881 \\
\hline $\mathrm{CP}$ & 1 & 0 & 0 & 2.057 \\
\hline Euskotren & 1 & 0 & 0 & 94.866 \\
\hline FGC & 1 & 0 & 0 & 35.144 \\
\hline RENFE & 1 & 0 & 0 & 2.216 \\
\hline $\mathrm{BDZ}$ & 1 & 0 & 0 & 0.943 \\
\hline $\mathrm{CD}$ & 1 & 0 & 0 & 0.798 \\
\hline EVR & 1 & 0 & 0 & 1.834 \\
\hline OSE & 1 & 0 & 0 & 2.833 \\
\hline GYSEV & 1 & 0 & 0 & 2.729 \\
\hline MAV & 1 & 0 & 0 & 0.979 \\
\hline LDZ & 1 & 0 & 0 & 1.340 \\
\hline LG & 1 & 0 & 0 & 1.362 \\
\hline PKP & 1 & 0 & 0 & 0.975 \\
\hline CFR & 1 & 0 & 0 & 1.042 \\
\hline ZSSK & 1 & 0 & 0 & 1.478 \\
\hline $\mathrm{SZ}$ & 1.319 & 0 & 3256 & 1.020 \\
\hline Average & 1.027 & & & \\
\hline
\end{tabular}


As mentioned, strong congestion implies weak congestion but not vice versa. Thus, we further investigate whether the selected 24 railways have weak congestion by Equations (9) and (10) and the results are indicated in Table 5. Moreover, the results of DSE calculated by Equation (11) are also presented. From Table 5, we note that 14 railways have negative DSE, indicating that they exhibit weak congestion. As for the output shortfall $\left(t^{+}\right)$, 14 railways can improve freight service by expanding 2585 million ton-kilometers and 8 railways can improve passenger service by expanding 1351 passenger-kilometers, on average, so as to eliminate the weak congestion. As for the excess inputs, based on our results, available capacity of freight transport service in terms of

Table 5. The results of weak congestion.

\begin{tabular}{|c|c|c|c|c|c|c|c|}
\hline \multirow{2}{*}{ Railways } & \multicolumn{4}{|c|}{$t^{-}$} & \multicolumn{2}{|c|}{$t^{+}$} & \multirow{2}{*}{ DSE } \\
\hline & $x_{1}$ & $x_{2}$ & $x_{3}$ & $x_{4}$ & $y_{1}$ & $y_{2}$ & \\
\hline GKB & 0 & 0 & 0 & 0 & 0 & 0 & 0 \\
\hline ÖBB & 0 & 608 & 0 & 24 & 3559 & 864 & -0.917 \\
\hline SNCB & 15 & 0 & 1940 & 0 & 0 & 106 & -2.829 \\
\hline VR & 0 & 290 & 2 & 63,084 & 239 & 923 & -0.325 \\
\hline SNCF & 0 & 0 & 0 & 0 & 0 & 0 & 0 \\
\hline DB AG & 0 & 0 & 0 & 0 & 0 & 0 & 0 \\
\hline FS & 0 & 930 & 4 & 758,425 & 3140 & 5632 & -0.762 \\
\hline CFL & 0 & 33 & 10,398 & 88,680 & 0 & 3911 & -19.40 \\
\hline $\mathrm{CP}$ & 0 & 8 & 23,261 & 11 & 0 & 757 & -2.309 \\
\hline $\begin{array}{c}\text { Euskot- } \\
\text { ren }\end{array}$ & 0 & 0 & 0 & 0 & 0 & 0 & 0 \\
\hline FGC & 0 & 0 & 0 & 0 & 0 & 0 & 0 \\
\hline RENFE & 0 & 0 & 0 & 0 & 0 & 0 & 0 \\
\hline $\mathrm{BDZ}$ & 0 & 255 & 2 & 221,804 & 1102 & 12,018 & -5.513 \\
\hline $\mathrm{CD}$ & 0 & 1225 & 0 & 646,058 & 12,803 & 3761 & -2.108 \\
\hline EVR & 0 & 0 & 0 & 0 & 0 & 0 & 0 \\
\hline OSE & 0 & 111 & 9449 & 38,742 & 0 & 363 & -1.251 \\
\hline GYSEV & 0 & 0 & 0 & 0 & 0 & 0 & 0 \\
\hline MAV & 9723 & 313 & 0 & 0 & 3219 & 12,286 & -3.332 \\
\hline LDZ & 0 & 0 & 0 & 0 & 0 & 0 & 0 \\
\hline LG & 0 & 55 & 2 & 255,401 & 667 & 881 & -3.630 \\
\hline PKP & 0 & 0 & 0 & 0 & 0 & 0 & 0 \\
\hline CFR & 0 & 13 & 0 & $1,388,446$ & 7705 & 14,453 & -3.918 \\
\hline ZSSK & 2299 & 0 & 71,337 & 536,493 & 0 & 4962 & -1.159 \\
\hline $\mathrm{SZ}$ & 616 & 29 & 0 & 4 & 0 & 1117 & -3.071 \\
\hline Average & 527 & 161 & 4850 & 166,549 & 1351 & 2585 & \\
\hline
\end{tabular}

number of tonnages is the most urgent input factor to be contracted. This finding is somewhat different from that concluded in the previous studies, which suggested that overstaffing is the most serious problem.

\section{Discussions and Concluding Remarks}

In the past two decades, many researchers have measured the rail transport efficiencies by standard DEA approaches without taking the input congestion into account. They found that railways, in general, over-utilized the labor. Since standard DEA approaches cannot deal with the input congestion, this study adopts the DEA extension method proposed by Tone and Sahoo [8] to analyze the efficiency and input congestion for some selected 24 EU railways. In contrast to previous relevant works, we redefine the number of employees, available capacity of passenger transport (in terms of number of seats), available capacity of freight transport (in terms of number of tonnages), and number of locomotives as four input variables. To assure the data homogeneity, we divide the selected EU railways into Western and Eastern groups and then test the difference of efficiency rankings between these two groups. The results show that there is no significant difference between these two groups, suggesting the homogeneity of the selected samples.

Our results indicate that the average output-oriented efficiency of these 24 EU railways is 1.353 , based on BCC model, suggesting that the overall EU railways should expand their outputs by 35.3 percent to achieve efficient. Of the 24 railways, 10 have been evaluated as technically efficient with no input or output slacks. The remaining 14 railways are inefficient, which should increase their passenger and freight transport services, keeping current inputs usage, especially for FS (Italy), OSE (Greece) and LG (Lithuania).

Our results also show that the scale elasticities are all greater than zero, implying that there is no strong congestion for the 24 EU railways. However, the results indicate that 14 EU railways exhibit weak congestion, of which eight belong to Eastern Europe and six belong to Western. Our empirical results also reveal that $12 \mathrm{EU}$ railways present weak congestion in available capacity of freight transport, amounted to 166,549 tons, which is the most congestive among four input factors; followed by the number of locomotives, amounted to 161 locomotives. It suggests that reduction in freight cars and locomotives is the important issue for these 12 railways. Moreover, 7 and 4 railways exhibit weak congestion in the number of seats and the number of employees amounted to 4850 seats and 527 employees, respectively. Based on these findings, the input urgently required being contracted in most EU railways is the available capacity of freight transport (tonnages), not the number of employees suggested by some previous studies which did 
not take the input congestion into consideration while measuring the efficiency.

Privatization is perhaps the most effective means in treating the excessive inputs of transport industries. The governments were aware of the disadvantages of public-owned entities, thus some EU railways have undergone a very favorable reformation. For example, the separation of ownership and operational management between the infrastructure and the transport services was initiated in Sweden in 1988. Banverket (BV), a new company, became responsible for the maintenance of track network, while SJ (Swedish Railways) was responsible for transport services. In 2001, the transport services were further divided into two parts: the Green Cargo is a logistics company transporting goods, while SJ operates passenger transport business. Likewise, other European countries such as Denmark, Netherlands, and Norway also underwent the similar reformation for their rail transport. We conclude that those railways with input congestion should learn from the benchmarked companies to eliminate the input congestion and further to enhance the productive efficiency.

Different operation scale (in terms of the length of line), rail technologies (electrified versus diesel), ownerships (public versus private), and socio-economic environment (e.g., population density and gross income per capita) may be associated with different levels of input slacks or congestion. Therefore, one promising avenue for future study is to investigate the effects of these internal and external factors on the input slacks or congestion. In addition, examination of rail transport efficiencies and input congestion over multiple years also deserve further exploration.

\section{Acknowledgements}

The authors are indebted to the anonymous reviewer for the insightful comments and constructive suggestions to level up the quality of this paper.

\section{REFERENCES}

[1] I. Lewis, J. Semeijn and D. B. Vellenga, "Issues and Initiatives Surrounding Rail Freight Transportation in Europe," Transportation Journal, Vol. 41, No. 2-3, 2001, pp. 23-31.

[2] C. Fleming, "Train Drain: In the Unified Europe Shipping Freight by Rail Is a Journey into the Past," The Wall Street Journal, Vol. 29, 1999, pp. A1-A8.

[3] L. W. Lan and E. T. J. Lin, "Performance Measurement for Railway Transport: Stochastic Distance Functions with Inefficiency and Ineffectiveness Effects," Journal of Transport Economics and Policy, Vol. 40, No. 3, 2006, pp. 383-408.

[4] R. Färe, S. Grosskopf and C. A. K. Lovell, "The Meas- urement of Efficiency of Production," Kluwer-Nijhoff Publishing, Boston, 1985.

[5] W. W. Cooper, L. M. Seiford and J. Zhu, "A Unified Additive Model Approach for Evaluating Inefficiency and Congestion with Associated Measures in DEA," SocioEconomic Planning Sciences, Vol. 34, No. 1, 2000, pp. 1-25. doi:10.1016/S0038-0121(99)00010-5

[6] W. W. Cooper, B. Gu and S. Li, "Comparisons and Evaluations of Alternative Approaches to the Treatment of Congestion in DEA," European Journal of Operational Research, Vol. 132, No. 1, 2001, pp. 62-74. doi:10.1016/S0377-2217(00)00113-2

[7] Q. Wei and H. Yan, "Congestion and Returns to Scale in Data Envelopment Analysis," European Journal of Operational Research, Vol. 153, No. 3, 2004, pp. 641-660. doi:10.1016/S0377-2217(02)00799-3

[8] K. Tone and B. K. Sahoo, "Degree of Scale Economies and Congestion: A Unified DEA Approach," European Journal of Operational Research, Vol. 158, No. 3, 2004, pp. 755-772. doi:10.1016/S0377-2217(03)00370-9

[9] A. Charnes, W. W. Cooper and E. Rhodes, "Measuring the Efficiency of Decision Making Units," European Journal of Operational Research, Vol. 2, No. 6, 1978, pp. 429444. doi:10.1016/0377-2217(78)90138-8

[10] T. H. Oum and C. Yu, "Economic Efficiency of Railways and Implications for Public Policy: A Comparative Study of the OECD Countries' Railways," Journal of Transport Economics and Policy, Vol. 28, No. 2, 1994, pp. 121-138.

[11] A. Chapin and S. Schmidt, "Do Mergers Improve Efficiency," Journal of Transport Economics and Policy, Vol. 33, No. 2, 1999, pp. 147-162.

[12] J. Cowie, "The Technical Efficiency of Public and Private Ownership in the Rail Industry: The Case of Swiss Private Railways," Journal of Transport Economics and Policy, Vol. 33, No. 3, 1999, pp. 241-252.

[13] L. W. Lan and E. T. J. Lin, "Measuring Railway Performance with Adjustment of Environmental Effects, Data Noise and Slacks," Transportmetrica, Vol. 1, No. 2, 2005, pp. 161-189. doi:10.1080/18128600508685645

[14] R. Färe and L. Svensson, "Congestion of Production Factors," Econometrica, Vol. 48, No. 7, 1980, pp. 1745-1753. doi: $10.2307 / 1911932$

[15] W. W. Cooper, R. G. Thompson and R. M. Thrall, "Introduction: Extension and New Developments in DEA," Annals of Operations Research, Vol. 66, No. 1, 1996, pp. 3-45. doi:10.1007/BF02125451

[16] P. L. Brockett, W. W. Cooper, Y. Wang and H. Shin, "Inefficiency and Congestion in Chinese Production before and after the 1978 Economic Reform," Socio-Economic Planning Science, Vol. 32, No. 1, 1998, pp. 1-20. doi:10.1016/S0038-0121(97)00020-7

[17] M. J. Farrell, "The Measurement of Productive Efficiency," Journal of the Royal Statistical Society: Series A, Vol. 120, No. 3, 1957, pp. 253-290. doi:10.2307/2343100

[18] R. D. Banker, A. Charnes and W. W. Cooper, "Some Models for Estimating Technical and Scale Inefficiencies in Data Envelopment Analysis," Management Science, 
Vol. 58, No. 10, 1984, pp. 1078-1092. doi: $10.1287 / \mathrm{mnsc} .30 .9 .1078$

[19] A. I. Ali and L. M. Seiford, "The Mathematical Programing Approach to Efficiency Analysis," In: H. O. Fried, C. A. K. Lovell and S. S. Schmidt, Eds., The Measurement of Productive Efficiency: Techniques and Applications, Oxford University Press, New York, 1993, pp. 120-159.

[20] UIC, International Railway Statistics, International Union of Railways, Paris, 2006.

[21] B. Golany and Y. Roll, "An Application Procedure for DEA," International Journal of Management Science, Vol. 17, No. 3, 1989, pp. 237-250.
[22] T. J. Coelli and S. Perelman, "A Comparison of Parametric and Non-parametric Distance Functions: With Application to European Railways," European Journal of Operational Research, Vol. 117, No. 2, 1999, pp. 326-339. doi:10.1016/S0377-2217(98)00271-9

[23] T. J. Coelli and S. Perelman, "Technical Efficiency of European Railways: A Distance Function Approach," Applied Economics, Vol. 32, No. 15, 2000, pp. 1967-1976. doi:10.1080/00036840050155896

[24] R. E. Rosenthal, "GAMS: A User's Guide,” GAMS Development Corporation, Washington DC, 2008. 